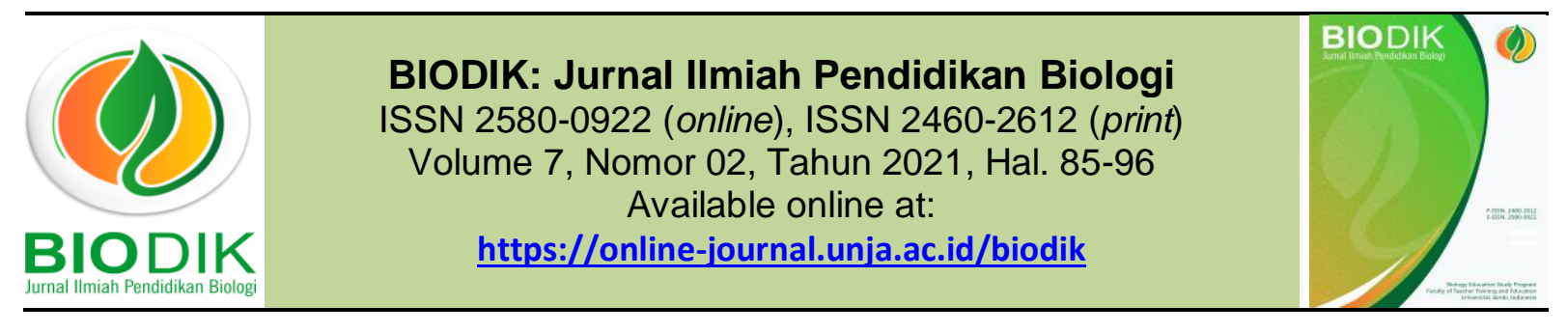

Research Article

\title{
Analisis dan Rekonstruksi Lembar Kegiatan Peserta Didik pada Materi Keanekaragaman Hayati
}

\author{
(Analysis and Reconstruction of Biodiversity Student's Worksheet)
}

\author{
Nissa Rachmawati ${ }^{\star}$, Bambang Supriatno, Sri Anggraeni \\ Program Studi Pendidikan Biologi Universitas Pendidikan Indonesia \\ JI. Dr. Setiabudi No. 229, Bandung 40154, Indonesia \\ Corresponding author: nissa.rachmawati@live.com
}

\begin{tabular}{|c|c|}
\hline Informasi Artikel & ABSTRACT \\
\hline \multirow[t]{2}{*}{$\begin{array}{l}\text { Submit: } 03-02-2021 \\
\text { Diterima: } 24-05-2021 \\
\text { Dipublikasikan: } 02-06-2021\end{array}$} & $\begin{array}{l}\text { Practical activities are known to be able to develop 21st century skills and higher- } \\
\text { order thinking skills to solve various problems but the existing student worksheets as } \\
\text { supporting material are not yet optimal. The purpose of this study was to analyze and } \\
\text { to reconstruct biodiversity student worksheet. The research method is descriptive } \\
\text { quantitative with the ANCOR (Analysis-Try-Reconstruction) model. The analysis } \\
\text { process is based on aspects of curriculum relevance, competence and knowledge } \\
\text { construction. Then a trial was conducted on one of the student worksheets. The } \\
\text { findings from the analyzes and trials formed the basis for reconstructing the } \\
\text { biodiversity student worksheets. The results showed that the existing student } \\
\text { worksheets had not yet developed higher-order thinking skills, the title / goal had not } \\
\text { focused on the main things related to the object and the lack of concepts formed. The } \\
\text { results of the reconstruction of student worksheets include the addition of tools and } \\
\text { materials, table revisions, and discuss questions that can develop higher-order } \\
\text { thinking skills. }\end{array}$ \\
\hline & Key words: practical activities, biodiversity, student's worksheets, HOTS, ANCOR \\
\hline Penerbit & ABSTRAK \\
\hline $\begin{array}{l}\text { Program Studi Pendidikan Biologi } \\
\text { FKIP Universitas Jambi, } \\
\text { Jambi- Indonesia }\end{array}$ & $\begin{array}{l}\text { Kegiatan praktikum diketahui mampu mengembangkan keterampilan abad } 21 \text { dan } \\
\text { kemampuan berpikir tingkat tinggi agar bisa menyelesaikan permasalahan } \\
\text { keanekaragaman hayati namun LKPD yang ada sebagai penunjang praktikum belum } \\
\text { optimal. Tujuan penelitian ini adalah menganalisis dan merekonstruksi LKPD materi } \\
\text { keanekaragaman hayati. Metode penelitian menggunakan deskriptif kuantitatif } \\
\text { dengan model ANCOR (Analisi-Coba-Rekonstruksi). Proses analisis berdasarkan } \\
\text { aspek relevansi kurikulum, kompetensi dan konstruksi pengetahuan. Lalu dilakukan } \\
\text { uji coba pada salah satu LKPD. Temuan dari analisis dan uji coba menjadi dasar } \\
\text { rekonstruksi LKPD keanekaragaman hayati. Hasil penelitian menunjukkan bahwa } \\
\text { LKPD yang ada masih belum mengembangkan kemampuan berpikir tingkat tinggi, } \\
\text { judul/tujuan belum fokus terhadap hal utama yang berkaitan dengan objek dan masih } \\
\text { minimnya konsep yang terbentuk. Hasil rekonstruksi LKPD terdapat penambahan } \\
\text { alat dan bahan, revisi tabel pengamatan dan pertanyaan diskusi yang dapat } \\
\text { mengembangkan kemampuan berpikir tingkat tinggi. }\end{array}$ \\
\hline & $\begin{array}{l}\text { Kata kunci: praktikum, keanekaragaman hayati, lembar kerja peserta didik, HOTS, } \\
\text { ANCOR }\end{array}$ \\
\hline
\end{tabular}


This BIODIK : Jurnal IImiah Pendidikan Biologi is licensed under a CC BY-NC-SA (Creative Commons Attribution-ShareAlike 4.0 International License)

\section{PENDAHULUAN}

Keanekaragaman hayati mengacu pada keragaman dan variabilitas alami diantara organisme hidup, kompleks ekologi tempat organisme berada dan cara berinteraksi baik antara satu organisme dengan organisme lain ataupun dengan lingkungannya (Redford \& Richter, 1999). Keanekaragaman hayati dapat meningkatkan ketahanan ekosistem terhadap berbagai peristiwa iklim (Isbell et al., 2015). Beberapa penelitian melaporkan peristiwa kepunahan massal ke enam atau the sixth great mass extinction sedang terjadi dan ditandai oleh penurunan keanekaragaman hayati secara besar-besaran (Wolff \& Skarstein, 2020). Hal ini memunculkan keprihatinan dalam skala global (Olomola et al., 2019). Ancaman kepunahan keanekaragaman hayati juga tidak terlepas walaupun suatu negara tersebut merupakan negara yang memiliki tingkat keragaman hayati yang tinggi. Tepat setelah hutan hujan Amazon, Indonesia memiliki keanekaragaman hayati terbesar kedua di dunia (Elfahmi et al., 2014). Sangat disayangkan ketika Indonesia hanya menempati $1 \%$ daratan dunia dengan keragaman spesies asli yang tinggi namun menyumbang hampir 191 spesies mamalia dan 160 spesies burung diantaranya kini mulai langka (Madden, 2019). Untuk mengatasi masalah mendesak terkait dengan hilangnya keanekaragaman hayati, diperlukan perubahan kesadaran perilaku dari para pengambil keputusan di semua sektor (Tinch et al., 2018).

UNESCO menyampaikan bahwa pendidikan berperan penting dalam menjaga kelangsungan keanekaragaman hayati. Siswa hari ini akan menjadi pengambil keputusan di kemudian hari sehingga mengenalkan keanekearagaman hayati dan meningkatkan kesadaran akan upaya pelestariannya sangatlah penting. Pendidikan biologi di masa kini perlu fokus pada isu-isu sosio-saintifik untuk mempersiapkan siswa berpartisipasi aktif dalam proses pengambilan keputusan yang melibatkan aspek sains dan membekali siswa dengan keterampilan abad ke-21 diharapkan dapat menjadi solusi yang baik (Schneiderhan-Opel \& Bogner, 2020). Keterampilan abad ke-21 dapat diukur dengan melihat bagaimana siswa dapat berpikir kritis, memiliki kreativitas, berkolaborasi dan komunikasi atau dikenal dengan 4C. Keterampilan $4 \mathrm{C}$ ini dapat diukur dengan melihat bagaimana nilai keterampilan berpikir tingkat tinggi siswa (Yulianto et al., 2019). Keterampilan berpikir tingkat tinggi, siswa tidak hanya mengingat dan menghapal tapi juga mampu menghubungkan, memanipulasi, serta melakukan transformasi pengetahuan dan pengalaman yang telah dimiliki sebelumnya (Putri et al., 2018).

Keterampilan-keterampilan yang dikembangkan secara manual, khususnya kerja praktik atau praktikum, sangat diperlukan dalam mempelajari biologi, termasuk keanekaragaman hayati. Hal ini dikarenakan praktikum dapat mengkontruksi keterampilan psikomotorik, mengkarakterisasi hasil belajar serta berfikir tingkat tinggi (Supriatno, 2018). Praktikum merupakan metode yang efektif dalam mencapai tujuan pembelajaran dan praktikum sendiri memiliki tujuan agar siswa mampu mengaplikasikan teori yang dimiliki baik menggunakan fasilitas laboratorium maupun di luar laboratorium (Juhanda et al., 2021). Kegiatan praktikum yang akan dilakukan oleh siswa biasanya akan disertai dengan penggunaan sebuah lembar kerja peserta didik (LKPD). LKPD yang digunakan di sekolah kebanyakan berasal dari buku referensi ataupun hasil buatan guru sendiri. Namun berdasarkan penelitian Supriatno (2018) LKPD yang ada di lapangan masih memiliki banyak kelemahan baik dari 
segi konten, perolehan pengetahuan ataupun belum adanya keselarasan antara tujuan dengan langkah kerja pada kegiatan praktikum yang termuat dalam LKPD.

LKPD keanekaragaman hayati di Indonesia dapat dibilang cukup banyak mengingat materi ini telah ada di dalam kurikulum Indonesia sejak tahun 1994. Setiap kali kurikulum di Indonesia berganti, LKPD-LKPD baru muncul menyesuaikan dengan tuntutan kurikulum. Pengembangan LKPD berdasarkan hasil analisis kurikulum telah banyak dilakukan misalnya pada materi struktur dan fungsi sel (Angreani et al., 2020), struktur darah (Handayanie et al., 2020), klasifikasi spermatofita (Ekselsa et al., 2020). Namun sejauh ini belum ada penelitian yang menganalisis LKPD keanekaragaman hayati dari kurikulum terdahulu hingga kurikulum terbaru. Dengan melihat tren LKPD keanekaragaman hayati dari berbagai kurikulum diharapkan dapat melihat apakah LKPD keanekaragaman hayati yang digunakan di sekolah-sekolah dari dulu hingga sekarang telah memenuhi kompetensi yang diminta dalam kurikulum. Maka dari itu, penelitian ini bertujuan untuk menganalisis LKPD keanekaragaman hayati dari berbagai kurikulum yang ada di Indonesia dan dari hasil analisis tersebut dilakukan rekonstruksi LKPD keanekaragaman hayati.

\section{METODE PENELITIAN}

Kegiatan analisis dilakukan secara deskriptif kuantitatif untuk menggambarkan keadaan LKPD Keanekaragaman Hayati. Teknik pengumpulan data menggunakan purposive sampling. Populasi penelitian yaitu lembar kerja peserta didik (LKPD) SMA kelas X. Sampel yang dianalisis adalah sembilan LKPD keanekaragaman hayati dari berbagai kurikulum diantaranya 2 LKPD dari kurikulum 1994, 1 LKPD kurikulum 2004, 2 LKPD kurikulum 2006, 2 LKPD kurikulum 2013 dan 2 LKPD kurikulum 2013 revisi. Instrumen yang digunakan dalam penelitian ini adalah rubric analisis LKPD untuk aspek relevansi dengan kurikulum, kompetensi, dan konstruksi pengetahuan. . Langkah yang digunakan pada penelitian ini adalah adalah langkah yang dikembangkan oleh (Supriatno dalam Nurpratiwi, 2020) yaitu Analisis, Uji Coba dan Rekonstruksi (ANCOR).

Tahap pertama yaitu melakukan pengumpulan LKPD kelas $\mathrm{X}$ mengenai materi keanekaragaman hayati dari berbagai kurikulum. Tahap selanjutnya menganalisis sembilan LKPD yang telah dikumpulkan menggunakan instrument rubric analisis LKPD. Kegiatan menganallisis bertujuan untuk melihat relevansi dengan kurkulum yang berlaku saat LKPD tersebut dibuat, melihat aspek kompetensi dan konstruksi pengetahuan. Setelah dilakukan analisis, salah satu LKPD dipiih untuk di uji coba. LKPD yang dipilih merupakan LKPD dari kurikulum terbaru. Uji coba dilakukan mengikuti petunjuk yang ada pada LKPD. Berdaasarkan hasil temuan analisis dan uji coba, tahap terakhir yaitu merekonstruksi dan membuat LKPD dengan memperbaiki permasalahan yang ada pada LKPD sebelumnya. Adapun bagan prosedur penelitian dapat dilihat di Gambar 1.

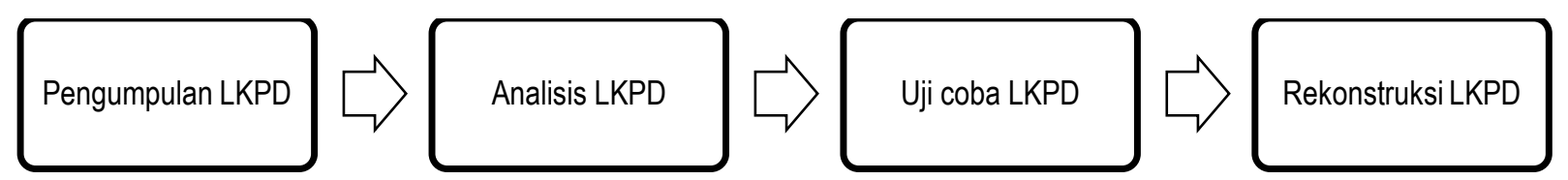

Gambar 1. Bagan Prosedur Penelitian 


\section{HASIL PENELITIAN DAN PEMBAHASAN}

\section{Hasil Analisis Relevansi Kurikulum, Kompetensi dan Konstruksi Pengetahuan}

Sembilan LKPD keanekaragaman hayati telah melalui tahap analisis dari berbagai aspek, diantaranya 2 LKPD dari kurikulum 1994, 1 LKPD kurikulum 2004, 2 LKPD kurikulum 2006, 2 LKPD kurikulum 2013 dan 2 LKPD kurikulum 2013 revisi. Aspek pertama yaitu relevansi dengan kurikulum. Tujuan dari aspek relevansi untuk melihat kesesuaian antara LKPD dengan KD pada kurikulum yang berlaku saat LKPD tersebut dibuat. Aspek relevansi dapat diukur dari kompetensi dan konten LKPD telah memenuhi standar minimal KD yang telah ditentukan dalam kurikulum. Perolehan skor hasil analisis ketiga aspek tersebut ditunjukkan pada Tabel 1.

Tabel 1. Perolehan Skor Analisis LKPD pada Aspek Relevansi Kurikulum

\begin{tabular}{|c|c|c|c|c|c|c|c|c|c|c|c|}
\hline \multirow{3}{*}{ Indikator } & \multirow{3}{*}{$\begin{array}{c}\text { Skor } \\
\text { maksimum }\end{array}$} & \multicolumn{9}{|c|}{ LKPD Kurikulum } & \multirow{3}{*}{$\begin{array}{c}\text { Persentase } \\
\text { per } \\
\text { indikator }\end{array}$} \\
\hline & & \multicolumn{2}{|c|}{1994} & 2004 & \multicolumn{2}{|c|}{2006} & \multicolumn{2}{|c|}{2013} & \multicolumn{2}{|c|}{$\begin{array}{c}2013 \\
\text { Revisi }\end{array}$} & \\
\hline & & $A$ & $B$ & C & $D$ & $E$ & $\mathrm{~F}$ & $G$ & $\mathrm{H}$ & I & \\
\hline \multirow{2}{*}{ Kompetensi dengan KD } & \multirow{2}{*}{3} & \multirow{2}{*}{2} & \multirow{2}{*}{2} & \multirow{2}{*}{1} & \multirow{2}{*}{2} & \multirow{2}{*}{2} & \multirow{2}{*}{2} & \multirow{2}{*}{2} & \multirow{2}{*}{2} & \multirow{2}{*}{2} & $2=89 \%$ \\
\hline & & & & & & & & & & & $1=11 \%$ \\
\hline \multirow[t]{2}{*}{ Konten dengan KD } & \multirow[t]{2}{*}{3} & \multirow[t]{2}{*}{2} & \multirow[t]{2}{*}{2} & \multirow[t]{2}{*}{2} & \multirow[t]{2}{*}{2} & \multirow{2}{*}{2} & \multirow[t]{2}{*}{3} & \multirow{2}{*}{3} & \multirow{2}{*}{2} & \multirow{2}{*}{2} & $3=22 \%$ \\
\hline & & & & & & & & & & & $2=78 \%$ \\
\hline
\end{tabular}

Hasil analisis menunjukkan bahwa pada indikator kompetensi diperoleh 89\% LKPD telah memenuhi standar minimal KD. Namun, LKPD C pada kurikulum 2004 merupakan satu-satunya LKPD yang kompetensinya belum memenuhi standar minimal KD. Hal ini dikarenakan standar minimal kompetensi mengenai materi keanekargaaman hayati berbeda pada setiap kurikulumnya. Standar minimal kurikulum 2004 ialah merumuskan konsep keanekaragaman hayati melalui kegiatan pengamatan terhadap lingkungan sekitarnya. Tetapi kegiatan praktikum LKPD C hanya melakukan pengamatan dari gambar yang disediakan dengan sedikit pertanyaan pengarah sehingga belum mampu mencapai standar minimal KD yang telah ditentukan. Kemudian, pada indikator konten, $78 \%$ LKPD telah memuat konten yang memenuhi standar minimal KD dan 22\% lainnya, yaitu LKPD $F$ dan LKPD G pada kurikulum 2013 telah melebihi standar minimal KD. Standar minimal KD yaitu memuat salah satu konsep keanekaragaman hayati baik pada level gen, spesies atau ekosistem, sedangkan untuk yang memuat ketiga level ditetapkan sebagai melebihi standar sehingga mendapat skor lebih besar.

LKPD keanekaragaman hayati kurikulum 1994 merupakan LKPD terdahulu yang dianalisis. Hal ini dikarenakan pada kurikulum 1986 tidak terdapat materi keanekaragaman hayati di dalam tujuan kurikuler dan tujuan instruksionalnya sehingga tidak dilakukan analisis. Jika dilihat dari konten baik dari kurikulum 1994 hingga 2013 revisi masih tetap sama. Namun dari segi kompetensi, perbedaan yang ada pada kurikulum 1994 hingga 2013 revisi adalah kata kerja operasional yang menjadi kompetensi dasar. Kurikulum 1994 hanya dituntut untuk memahami sedangkan tuntutan pada kurikulum 2004 yaitu merumuskan konsep, dan pada kurikulum 2006 mendeskripsikan konsep keanekaragaman hayati. Mulai dari kurikulum 2013 hingga 2013 revisi tuntutan kompetensi pada kurikulum meningkat menjadi 
menganalisis data hasil observasi keanekaragaman hayati. Kurikulum 2013 sebagai penyempurnaan dari kurikulum 2006, menitikberatkan pada pendalaman dan peluasan materi, penguatan proses pembelajaran dan penyesuaian agar dapat menyiapkan dan menghadapi tantangan global (Machali, 2014).

Aspek kedua yang telah dianalisis dari LKPD keanekaragaman hayati kurikulum 1994 hingga 2013 revisi yaitu aspek kompetensi. Pada aspek ini, indikator yang dipilih berfokus pada kemampuan observasi, kemampuan representasi data, kemampuan interpretasi data dan level kemampuan berpikir yang akan dicapai siswa saat menggunakan LKPD tersebut dalam kegiatan praktikum. Adapun perolehan skor aspek kompentensi setiap LKPD ditunjukkan pada Tabel 2.

Tabel 2. Perolehan Skor Analisis LKPD pada Aspek Kompetensi

\begin{tabular}{|c|c|c|c|c|c|c|c|c|c|c|c|}
\hline \multirow{3}{*}{ Indikator } & \multirow{3}{*}{$\begin{array}{c}\text { Skor } \\
\text { Maksimum }\end{array}$} & \multicolumn{9}{|c|}{ LKPD Kurikulum } & \multirow{3}{*}{$\begin{array}{c}\text { Persentase } \\
\text { per } \\
\text { indikator }\end{array}$} \\
\hline & & \multicolumn{2}{|c|}{1994} & 2004 & \multicolumn{2}{|c|}{2006} & \multicolumn{2}{|c|}{2013} & \multicolumn{2}{|c|}{$\begin{array}{l}2013 \\
\text { Revisi }\end{array}$} & \\
\hline & & A & B & C & $\mathrm{D}$ & $E$ & $\mathrm{~F}$ & G & $\mathrm{H}$ & I & \\
\hline \multirow{2}{*}{ Kemampuan Observasi } & \multirow{2}{*}{4} & \multirow{2}{*}{4} & \multirow{2}{*}{4} & \multirow{2}{*}{4} & \multirow{2}{*}{4} & \multirow{2}{*}{4} & \multirow{2}{*}{4} & \multirow{2}{*}{3} & \multirow{2}{*}{4} & \multirow{2}{*}{3} & $4=22 \%$ \\
\hline & & & & & & & & & & & $3=78 \%$ \\
\hline \multirow{3}{*}{$\begin{array}{c}\text { Kemampuan Representasi } \\
\text { Data }\end{array}$} & \multirow{3}{*}{4} & \multirow{3}{*}{3} & \multirow{3}{*}{4} & \multirow{3}{*}{2} & \multirow{3}{*}{4} & \multirow{3}{*}{3} & \multirow{3}{*}{4} & \multirow{3}{*}{4} & \multirow{3}{*}{4} & \multirow{3}{*}{3} & $4=56 \%$ \\
\hline & & & & & & & & & & & $3=33 \%$ \\
\hline & & & & & & & & & & & $2=11 \%$ \\
\hline \multirow{2}{*}{$\begin{array}{c}\text { Kemampuan Transformasi } \\
\text { Data }\end{array}$} & \multirow{2}{*}{4} & \multirow{2}{*}{1} & \multirow{2}{*}{1} & \multirow{2}{*}{1} & \multirow{2}{*}{2} & \multirow{2}{*}{2} & 2 & 2 & 2 & 1 & $2=56 \%$ \\
\hline & & & & & & & 2 & 2 & 2 & 1 & $1=44 \%$ \\
\hline Level Kemampuan Berpikir & 4 & 1 & 1 & 1 & 1 & 1 & 2 & 2 & 2 & 1 & $2=32 \%$ \\
\hline & & & & & & & & & & & $1=67 \%$ \\
\hline
\end{tabular}

Berdasarkan hasil analisis, dari indikator kemampuan observasi 78\% LKPD dari kurikulum 1994 hingga 2013 revisi sudah dapat mengobservasi karakter spesifik dari objek/fenomena dan mendukung perolehan pengetahuan. Sedangkan $22 \%$ lainnya hanya mampu mengobservasi karakter umum saja. Selain itu pada indikator representasi data, 56\% LKPD dari kurikulum 1994 hingga 2013 revisi data kualitatif nya sudah direpresentasikan ke dalam bentuk matriks dengan tepat dan membantu proses interpretasi data. 33\% LKPD lainnya sudah direpresentasikan ke dalam bentuk matriks dengan tepat namun belum dapat membantu proses interpretasi data dan 11\% hanya direpresentasikan ke dalam bentuk standar. Dari indikator interpretasi data, 56\% LKPD dari kurikulum 1994 hingga 2013 revisi sudah menggunakan komponen data pada matriks secara keseluruhan sedangkan 11\% LKPD proses interpretasinya hanya menggunakan beberapa komponen data saja. Indikator level kemampuan berpikir diperoleh 67\% LKPD kegiatan praktikum hanya melibatkan kemampuan berpikir level rendah atau lower order thinking skill sedangkan 32\% LKPD dalam kegiatan praktikumnya telah mampu mengembangkan kemampuan berpikir tingkat tinggi atau higher order thinking skill.

Dari empat indikator, kemampuan observasi, representasi data dan transformasi sudah menujukkan hasil yang baik. Namun pada indikator kemampuan berpikir, hasil menunjukkan masih banyaknya LKPD yang belum mengembangkan kemampuan berpikir tingkat tinggi. Tinggi nya skor tersebut dikarenakan kegiatan LKPD pada kurikulum 1994 hingga 2006 memang tidak dibuat untuk kemampuan berpikir tingkat tinggi serta tidak adanya tuntutan kurikulum untuk itu. Permasalahan muncul ketika LKPD I yang merupakan LKPD kurikulum 2013 revisi tidak dapat mengembangkan kemampuan berpikir tingkat tinggi padahal sudah ada dalam tuntutan kurikulum. Kemampuan berpikir tingkat tinggi dapat dikatakan berhasil apabila siswa terlibat di dalam pembelajaran dan mampu 
mengonstruksi penjelasan, berargumen dengan baik, memecahkan masalah dan memahami hal-hal kompleks yang mana kemampuan-kemampuan tersebut memperlihatkan bagaimana siswa menggunakan nalarnya (Sofyan, 2019). Dan LKPD sebagai teaching material supporting merupakan bagian dari fokus kemampuan berpikir tingkat tinggi (Ramli, 2015) .

Aspek terakhir merupakan aspek konstruksi pengetahuan yang diadaptasi dari Novak \& Gowin (1984). Perolehan skor aspek kompentensi setiap LKPD ditunjukkan pada Tabel 3.

Tabel 3. Perolehan Skor Analisis LKPD pada Aspek Kompetensi

\begin{tabular}{|c|c|c|c|c|c|c|c|c|c|c|c|}
\hline \multirow{3}{*}{ Indikator } & \multirow{3}{*}{$\begin{array}{c}\text { Skor } \\
\text { Maksimum }\end{array}$} & \multicolumn{9}{|c|}{ LKPD Kurikulum } & \multirow{3}{*}{$\begin{array}{c}\text { Persentase } \\
\text { per } \\
\text { indikator }\end{array}$} \\
\hline & & \multicolumn{2}{|c|}{1994} & 2004 & \multicolumn{2}{|c|}{2006} & \multicolumn{2}{|c|}{2013} & \multicolumn{2}{|c|}{$\begin{array}{l}2013 \\
\text { Revisi }\end{array}$} & \\
\hline & & A & $\mathrm{B}$ & C & $\mathrm{D}$ & $E$ & $\mathrm{~F}$ & G & $\mathrm{H}$ & I & \\
\hline \multirow{2}{*}{$\begin{array}{l}\text { Judul tujuan atau } \\
\text { pertanyaan fokus }\end{array}$} & \multirow{2}{*}{4} & \multirow{2}{*}{1} & \multirow{2}{*}{3} & \multirow{2}{*}{1} & \multirow{2}{*}{1} & \multirow{2}{*}{1} & \multirow{2}{*}{3} & \multirow{2}{*}{3} & \multirow{2}{*}{3} & \multirow{2}{*}{1} & $3=44 \%$ \\
\hline & & & & & & & & & & & $1=56 \%$ \\
\hline \multirow{2}{*}{ Objek/ fenomena } & \multirow{2}{*}{4} & \multirow{2}{*}{1} & \multirow{2}{*}{1} & \multirow{2}{*}{1} & \multirow{2}{*}{1} & \multirow{2}{*}{2} & \multirow{2}{*}{2} & \multirow{2}{*}{2} & \multirow{2}{*}{2} & \multirow{2}{*}{2} & $2=56 \%$ \\
\hline & & & & & & & & & & & $1=44 \%$ \\
\hline \multirow{2}{*}{ Teori, Prinsip dan Konsep } & \multirow{2}{*}{5} & \multirow{2}{*}{1} & \multirow{2}{*}{2} & \multirow{2}{*}{1} & 1 & 1 & 2 & 2 & 2 & 1 & $2=44 \%$ \\
\hline & & & & & & & & & & & $1=56 \%$ \\
\hline Perekaman dan & & & & & & & & & & & $4=11 \%$ \\
\hline transformasi data & 5 & 1 & 2 & 2 & 2 & 2 & 2 & 4 & 2 & 1 & $2=67 \%$ \\
\hline & & & & & & & & & & & $1=22 \%$ \\
\hline & & & & & & & & & & & $4=22 \%$ \\
\hline Perolehan Pencetahuan & 5 & 1 & 2 & 2 & 2 & 3 & 4 & 3 & 4 & 2 & $3=22 \%$ \\
\hline & & & & & & & & & & & $2=45 \%$ \\
\hline & & & & & & & & & & & $1=11 \%$ \\
\hline
\end{tabular}

Hasil analisis konstruksi pengetahuan menunjukkan bahwa 56\% LKPD keanekaragaman hayati dari kurikulum 1994 hingga 2013 revisi sudah terdapat judul/tujuan/pertanyaan fokus, tetapi belum memfokuskan kepada hal utama yang berkaitan dengan objek dan peristiwa sedangkan $11 \%$ lainnya judul/tujuan/pertanyaan fokus yang ada pada LKPD meliputi bagian konseptual yang dapat digunakan serta mendukung peristiwa utama dan memperkuat objek. Selain itu 56\% LKPD objek/fenomenanya sudah dapat diidentifikasi dan sudah konsisten dengan pertanyaan fokus namun $11 \%$ lainnya belum konsisten dengan pertanyaan fokus. Dari indikator ketiga, 56\% LKPD masih memiliki sedikit konsep yang dapat diidentifikasi dan belum terdapat prinsip-prinsip serta teori dan $44 \%$ lainnya terdiri dari banyak konsep. Kemudian, pada indikator perekaman dan transformasi data diperoleh 67\% LKPD dari kurikulum 1994 hingga 2013 revisi kegiatan pencatatan sudah dapat diidentifikasi. Terakhir pada indikator perolehan pengetahuan 45\% LKPD dari kurikulum 1994 hingga 2013 revisi perolehan pengetahuannya tidak konsisten dengan data dan atau peristiwa yang dicatat dan ditransformasikan.

Dari lima indikator yang dianalisis kemunculan objek/fenomena, perekaman dan transformasi data, serta perolehan pengetahuan sudah cukup baik. Tetapi pada indikator judul/tujuan/pertanyaan fokus masih banyak yang belum memfokuskan pada hal utama yang berkaitan dengan objek misalnya pada LKPD A tujuan praktikum bersifat umum untuk menunjukan keanekaragaman hayati, tapi kegiatan praktikum hanya pada level gen saja. Ada baiknya jika pada tujuan praktikum lebih difokuskan seperti pada LKPD B di kurikulum yang sama, tujuannya menyebutkan secara spesifik yaitu mengamati keanekaragaman jenis dan kegiatannya sesuai hanya mengobservasi keanekaragaman jenis saja. Selain itu pada indikator yang ketiga mengenai konsep yang diperoleh. Beberapa LKPD yang berfokus 
pada satu kegiatan saja, misalnya mengamati keanekaragaman level spesies saja hanya akan menghasilkan konsep yang sedikit. Berbeda dengan LKPD yang memuat ketiganya misalnya pada LKPD kurikulum 2013, selain tujuan relevan dengan kegiatan yang mencakup pengamatan di ketiga level, juga kaya akan konsep diantaranya konsep gen, konsep spesies dan konsep ekosistem. Walaupun sebenarnya standar minimal KD yang selanjutnya dibuat indikator tidak dilakukan dalam kegiatan praktikum, bukan berarti tidak dilaksanakan tetapi mungkin akan dilaksanakan pada pembelajaran di kelas. Tetapi karena LKPD merupakan penuntun praktikum, untuk LKPD yang hanya memuat satu konsep diberikan skor yang lebih kecil.

\section{Hasil Uji Coba (Analisis Praktikal)}

Setelah melakukan analisis dari aspek relevansi kurikulum, kompetensi dan konstruksi pengetahuan, tahap selanjutnya adalah melakukan uji coba pada salah satu LKPD dari kurikulum terbaru yaitu 2013 revisi. Pemilihan LKPD tersebut didasarkan pada kurikulum yang diterapkan di kebanyakan sekolah adalah 2013 revisi dan kurikulum sebelum-sebelumnya sudah jarang digunakan. Kegiatan uji coba kemudian dianalisis secara praktikal. Adapun tahapan-tahapan praktikum pada salah satu LKPD ditunjukkan pada tabel 4.

Tabel 4. Tahapan-tahapan Uji Coba LKPD Praktikum Keanekaragaman Hayati

Judul: Tingkat Keanekaragaman Hayati

Tujuan: Mengetahui keanekaragaman hayati di tingkat gen, spesies dan ekosistem

Langkah kerja:

1. Pergilah ke suatu ekosistem, misalnya kebun, kolam atau halaman sekolah

2. Catatlah semua organisme yang hidup di ekosistem tersebut dan amati ciri-cirinya

3. Jika terdapat organisme yang tergolong satu spesies, tetapi berbeda varietas atau memiliki perbedaan ciri tertentu (misalnya, perbedaan warna bunga), gunakan symbol $A, B, C$ dan seterusnya.

4. Kelompokkan organisme yang berbeda spesies, tetapi memiliki ciri-ciri fisik yang mirip

5. Tuliskan manfaat organisme yang telah anda catat

6. Tuliskan data-datanya ke dalam tabel pengamatan seperti berikut

Tabel pengamatan:

\begin{tabular}{|c|c|c|c|c|}
\hline \multirow{2}{*}{ No. } & \multicolumn{2}{|c|}{ Jenis Organisme } & Manfaat & \multirow{2}{*}{ Keterangan } \\
\cline { 2 - 3 } & Nama daerah & Nama ilmiah & Bahan Pangan & \\
\hline 1 & Padi & Oryza sativa & Aerasi tanah & \\
\hline 2 & Semut kecil & Monomorium $s p$. & Menjaga keseimbangan populasi & \\
\hline 3 & Laba-laba & Menemerangga & \\
\hline 4 & Semut besar & Camponotus $s p$. & Mengkompos kayu lapuk & \\
\hline 5 & Pohon jarak & Ricinus communis & Dibuat minyak & \\
\hline 6 & Ikan sawah & Aplocheilus $s p$. & Menanggulangi jentik & \\
\hline 7 & Tumbuhan paku & Marsilea sp. & Kelembaban tanah & \\
\hline 8 & Serangga air & Gerris $s p$. & Menanggulangi jentik & \\
\hline
\end{tabular}

Hasil uji coba praktikum

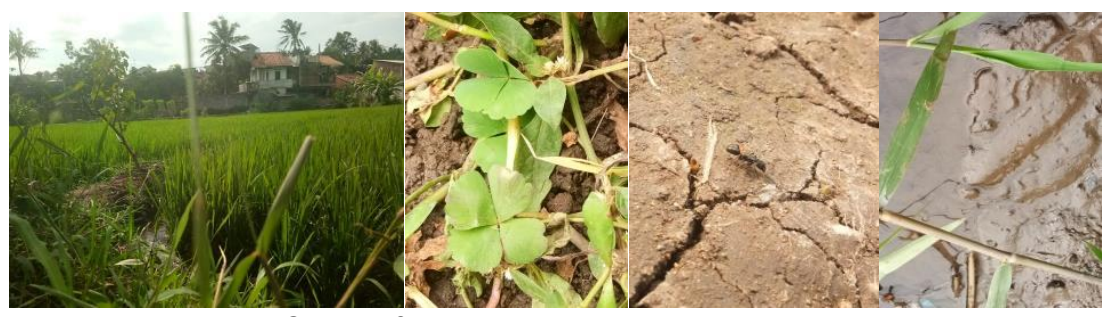

Gambar 2. Dokumentasi Hasil Pengamatan

(Sumber: Dokumentasi pribadi, 2021) 
Berdasarkan hasil analisis praktikal, LKPD keanekaragaman hayati dari segi konten dan kompetensi telah memenuhi standar minimal KD. 4.2 pada kurikulum 2013 revisi yaitu menyajikan hasil observasi berbagai tingkat keanekaragaman hayati di Indonesia dan usulan upaya pelestariannya. Namun ketika dilakukan uji coba belum memuat alat dan bahan sehingga saat peneliti melakukan uji coba tidak membawa apa apa ke lapangan. Kemudian, terdapat ketidaksesuaian antara langkah kerja dengan pertanyaan diskusi. Pada langkah kerja juga memuat perintah yang tidak relevan dengan tujuan praktikum. Tabel pengamatan belum bisa memuat semua data sesuai dengan tujuan praktikum, sehingga ketika menjawab pertanyaan pengarah hanya beberapa komponen saja yang bisa didapatkan dari tabel pengamatan. Dari pertanyaan pengarah hanya bisa menemukan konsep spesies saja sedangkan tujuan praktikum pada LKPD tersebut menuntut untuk sampai konsep gen dan ekosistem.

\section{Hasil Rekonstruksi}

Berdasarkan hasil temuan yang didapatkan dari analisis relevansi dengan kurikulum, kompetensi, konstruksi pengetahuan, dan uji coba, menjadi dasar untuk melakukan rekonstruksi LKPD keanekaragaman hayati. LKPD direkonstruksi dengan membuat LKPD yang dapat mengembangkan kemampuan berpikir tingkat tinggi siswa serta mengintegrasikan dengan pemanfaatan teknologi. Adapun rekonstruksi LKPD ditunjukkan pada tabel 5.

Tabel 5. LKPD Hasil Rekonstruksi

\section{TINGKAT KEANEKARAGAMAN HAYATI}

Bagaimanakah perbedaan keanekaragaman hayati pada tingkat gen, spesies dan ekosistem?

\section{Kompetensi Dasar:}

4.2 Menyajikan hasil observasi berbagai tingkat keanekaragaman hayati di Indonesia dan usulan upaya pelestariannya

Tujuan:

Membedakan keanekaragaman hayati tingkat gen, spesies dan ekosistem berdasarkan hasil observasi

Teori:

Mulai dari ikan koi di kolam yang berwarna-warni, dari bakteri mikroskopik hingga paus biru, dari daerah yang panas seperti gurun pasir hingga daerah yang dingin seperti kutub, kehidupan di muka bumi sangatlah beragam. Convention of Biological Diversity mendefinisikan keanekaragaman hayati sebagai keberagaman semua makhluk hidup pada tingkat gen, spesies dan ekosistem. Kehidupan manusia dan organisme lainnya sangat bergantung pada keanekaragaman hayati sehingga upaya untuk melestarikannya menjadi tanggung jawab setiap orang. Mengenali dan meningkatkan pengetahuan tentang keanekaragaman hayati dapat menjadi langkah pertama dalam mendukung upaya pelestarian.

\section{Kegiatan Praktikum:}

Pada kegiatan praktikum ini, siswa diminta untuk membedakan keanekaragaman hayati tingkat gen, spesies dan ekosistem berdasarkan hasil observasi

\section{Alat dan Bahan:}

Alat:

a. Alat tulis

Bahan:

b. Smartphone

Makhluk hidup asli di lingkungan sekitar

Langkah Kerja:

Perhatian: Perhatikan keamanan dan keselamatan kerja saat melakukan praktikum!

Kegiatan A

1. Buatlah sebuah kelompok yang terdiri dari 4 orang

2. Setelah berkumpul dalam kelompok, amatilah persamaan suatu spesies. Kegiatan ini bisa di dapat dari 
mengamati persamaan ciri-ciri fisikmu dan teman-teman satu kelompokmu

3. Amati juga perbedaan ciri-ciri fisikmu dan teman satu kelompokmu. Perbedaan ciri fisik yang dapat diamati diantaranya:
a. Warna kulit (terang, gelap)
b. Bentuk muka (bulat, tirus)
c. Bentuk hidung (mancung, tidak mancung)
d. Cuping telinga (Menempel, menggantung)
e. Rambut (Lurus, bergelombang, keriting)

4. Tuliskan nama ilmiah dari spesies yang anda amati di tempat yang telah disediakan

5. Tuliskan hasil pengamatan kedalam tabel $\mathrm{A}$

\section{Kegiatan B}

1. Pergilah ke halaman sekolah bersama teman kelompokmu

2. Carilah lima makhluk hidup/spesies lain selain manusia yang dapat anda temukan di halaman sekolah

3. Tuliskan nama makhluk hidup yang telah dipilih dan nama ilmiahnya. Kegiatan ini dapat dibantu dengan menggunakan aplikasi Seek. Aplikasi dapat diunduh di playstore smartphonemu. Setelah aplikasi diinstall, arahkan kamera pada makhluk hidup/ spesies yang telah anda pilih. Kemudian aplikasi akan otomatis memberikan keterangan nama ilmiah dan literasi lainnya mengenai makhluk hidup/spesies tersebut

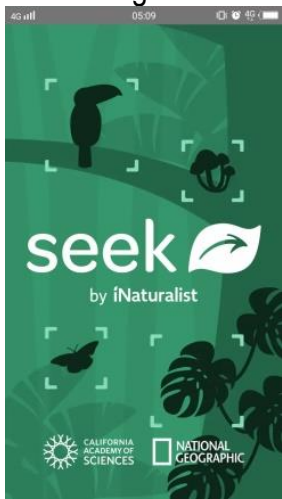

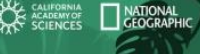

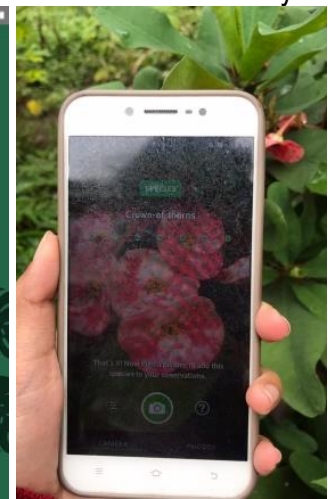

Gambar 3. Aplikasi Seek

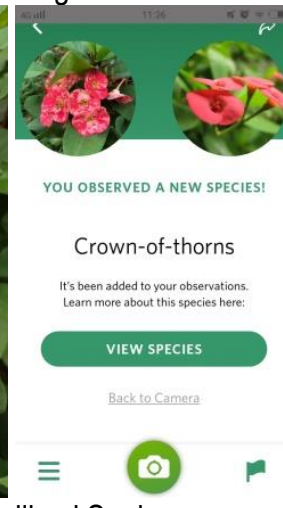

(Sumber: Dokumentasi Pribadi)

4. Amati ciri-ciri yang dimiliki oleh makhluk hidup/spesies tersebut

5. Tuliskan hasil pengamatan ciri serta informasi makhluk hidup/spesies yang telah dipilih kedalam tabel B

\section{Kegiatan C}

1. Masih di halaman sekolah, amatilah kondisi abiotik (komponen tak hidup seperti air, udara, cahaya, dII) dan makhluk hidup/spesies yang ada di halaman sekolah serta hitunglah jumlah makhluk hidup/organisme tersebut

2. Amatilah kondisi abiotik, jenis makhluk hidup/spesies yang ditemukan beserta jumlahnya!

3. Tuliskan hasil pengamatan ke dalam tabel C!

4. Pergilah ke suatu lingkungan selain halaman sekolah!

5. Di tempat yang anda pilih, amatilah kondisi abiotik, jenis makhluk hidup/spesies yang ditemukan beserta jumlahnya!

6. Tuliskan hasil pengamatan ke dalam tabel $\mathrm{Cl}$

Tabel Pengamatan:

Tabel A

\begin{tabular}{|l|l|l|l|l|l|}
\hline \multirow{2}{*}{$\begin{array}{c}\text { Persamaan ciri } \\
\text { yang dimiliki }\end{array}$} & \multicolumn{5}{|c|}{ Perbedaan ciri yang dimiliki } \\
\hline & Ciri penentu & Individu 1 & Individu 2 & Individu 3 & Individu 4 \\
\hline & Warna kulit & & & & \\
\cline { 2 - 6 } & Bentuk muka & & & & \\
\cline { 2 - 6 } & Bentuk hidung & & & & \\
\cline { 2 - 6 } & Cuping telinga & & & & \\
\cline { 2 - 6 } & Jenis rambut & & & & \\
\hline
\end{tabular}

Tabel B

\begin{tabular}{|c|c|c|c|}
\hline No. & Organisme & Nama ilmiah & Ciri-ciri \\
\hline 1 & & & \\
\hline 2 & & & \\
\hline 3 & & & \\
\hline 4 & & & \\
\hline 5 & & & \\
\hline
\end{tabular}




\begin{tabular}{|c|c|c|c|}
\hline Tabel C & & & \\
\hline & Kom & ng di identifikas & \\
\hline identifik & Komnonon tak hidun /Kondici Ahintik & Kompon & Biotik \\
\hline & komponen lak maup/ hondisi ADIOUIK & Jenis spesies & Jumlah \\
\hline Lingkungan & & & \\
\hline & & & \\
\hline & & & \\
\hline & & & \\
\hline Lingkungan & & & \\
\hline 等, & & & \\
\hline & & & \\
\hline & & & \\
\hline & & & \\
\hline
\end{tabular}

\section{Bahan Diskusi:}

Berdasarkan hasil pengamatan pada kegiatan A:

1. Apa jenis spesies yang anda amati?

2. Apa sajakah persamaan ciri yang dimiliki oleh spesies tersebut?

3. Apakah pada spesies yang sama juga terdapat perbedaan ciri? Jelaskan perbedaan ciri yang dapat ditemukan!

4. Dari manakah perbedaan ciri tersebut berasal?

5. Apakah kegiatan pengamatan keanekaragaman hayati yang anda lakukan di kegiatan A berada pada tingkat gen, spesies atau ekosistem? Berikan alasanmu!

Berdasarkan hasil pengamatan pada kegiatan $\mathrm{B}$ :

1. Apa sajakah jenis spesies yang anda amati?

2. Apakah dari ke lima jenis spesies tersebut memiliki perbedaan ciri? Jelaskan perbedaan tersebut!

3. Apakah kegiatan pengamatan keanekaragaman hayati yang anda lakukan di kegiatan B berada pada tingkat gen, spesies atau ekosistem? Berikan alasanmu!

Berdasarkan hasil pengamatan pada kegiatan C:

1. Adakah perbedaan kondisi abiotik dan jenis spesies diantara dua lingkungan yang anda amati? Jelaskan perbedaan tersebut!

2. Adakah persamaan jenis spesies diantara dua lingkungan tersebut? Jika ya, spesies pada lingkungan mana yang memiliki jumlah yang lebih banyak?

3. Faktor apakah yang dapat mempengaruhi persamaan dan perbedaan jenis serta jumlah spesies pada suatu lingkungan? Jelaskan pendapatmu!

4. Adakah pengaruh kegiatan manusia terhadap keadaan abiotik dan biotik yang anda amati? Jelaskan pendapatmu!

5. Apakah upaya yang dapat anda usulkan dalam menjaga kelestarian keanekaragaman hayati pada lingkungan tersebut!

6. Apakah kegiatan pengamatan keanekaragaman hayati yang anda lakukan di kegiatan $\mathrm{C}$ berada pada tingkat gen, spesies atau ekosistem? Berikan alasanmu!

Berdasarkan hasil pengamatan pada kegiatan A, B dan C:

1. Dapatkah anda membedakan berbagai tingkat keanekaragaman hayati?

2. Tuliskan kesimpulan dari ketiga kegiatan praktikum ini!

Pada LKPD rekonstruksi ini peneliti menambahkan komponen yang menjadi standar minimal KD 4.2 yaitu mengenai upaya pelestarian setelah menyajikan hasil observasi berbagai tingkat keanekaragaman hayati di Indonesia yang berarti memuat tingkat gen, spesies dan ekosistem. Selain itu, peneliti menambahkan komponen alat bahan pada LKPD keanekaragaman hayati dan merevisi tabel pengamatan. Langkah kerja direvisi menjadi lebih relevan dengan tujuan dan lebih terstruktur agar dapat mengarahkan peserta didik menemukan objek yang diamati. Pemanfaatan teknologi yaitu 
penggunaan aplikasi yang dapat membantu siswa dalam melihat nama spesies dan literasi mengenai spesies tersebut saat mengisi tabel pengamatan. Pertanyaan diskusi juga dibuat ulang agar peserta didik dapat mengembangkan kemampuan membaca data dan menarik kesimpulan mengenai perbedaan tingkat keanekaragaman hayati sehingga tujuan praktikum dapat tercapai.

\section{SIMPULAN}

LKPD keanekaragaman hayati dari kurikulum 1994 hingga 2013 revisi dianalisis menggunakan 4 aspek yaitu relevansi dengan kurikulum, kompetensi dan konstruksi pengetahuan. Hasil analisis menunjukan dari segi kompetensi maupun konten hampir seluruh LKPD telah relevan dengan kurikulum. Namun masih terdapat beberapa permasalahan pada aspek kompetensi dan konstruksi pengetahuan. Pada aspek kompetensi, permasalahan terletak pada level kemampuan berpikir yang dikembangkan masih rendah. Kemudian pada aspek konstruksi pengetahuan, permasalahan yang ada adalah judul atau tujuan belum memfokuskan terhadap hal utama yang berkaitan dengan objek serta minimnya konsep yang terbentuk. Solusi dari permasalahan ini adalah melakukan rekonstruksi LKPD sesuai dengan mempertimbangkan aspek relevansi, kompetensi dan konstruksi pengetahuan.

\section{UCAPAN TERIMA KASIH}

Penulis mengucapkan terimakasih sebesar-besarnya kepada Bapak Dr. Bambang Supriatno, M.Si dan Ibu Dr. Sri Anggraeni, M.Si selaku dosen pembimbing yang telah berbagi ilmu-ilmunya. Selain itu terimakasih saya ucapkan terimakasih kepada Bapak Ali Sadikin dari pihak Jurnal Biodik yang telah memfasilitasi informasi mengenai publikasi jurnal.

\section{RUJUKAN}

Anggi Angreani, Bambang Supriatno, \& Sri Anggraeni. (2020). Analisis, Uji Coba dan Rekontruksi Kegiatan Praktikum Melalui Lembar Kerja Peserta Didik Struktur dan Fungsi Sel. Jurnal Biodik, 6(3), 244-254. https://doi.org/10.22437/bio.v6i3.9467

Ekselsa, R. A., Supriatno, B., \& Anggraeni, S. (2020). Rekonstruksi dan Pengembangan Lembar Kerja Siswa pada Materi Plantae Submateri Spermatophyta dengan Pendekatan Keterampilan Proses. Jurnal Biodik, 6, 507-518. https://doi.org/10.22437/bio.v6i4.9505.

Elfahmi, Woerdenbag, H. J., \& Kayser, O. (2014). Jamu: Indonesian traditional herbal medicine towards rational phytopharmacological use. Journal of Herbal Medicine, 4(2), 51-73. https://doi.org/10.1016/j.hermed.2014.01.002

Handayanie, Y., Anggraeni, S., \& Supriatno, B. (2020). Analisis Lembar Kerja Siswa Praktikum Struktur Darah berbasis Diagram Vee. Jurnal Biodik, 6(3), 361-371. https://doi.org/10.22437/bio.v6i3.9408

Isbell, F., Craven, D., Connolly, J., Loreau, M., Schmid, B., Beierkuhnlein, C., Bezemer, T. M., Bonin, C., Bruelheide, H., De Luca, E., Ebeling, A., Griffin, J. N., Guo, Q., Hautier, Y., Hector, A., Jentsch, A., Kreyling, J., Lanta, V., Manning, P., ... Eisenhauer, N. (2015). Biodiversity increases the resistance of ecosystem productivity to climate extremes. Nature, 526(7574), 574-577. https://doi.org/10.1038/nature15374

Juhanda, A., Rustaman, N. Y., Hidayat, T., \& Wulan, A. R. (2021). Perspektif Penalaran Operasi Formal - Post Formal Mahasiswa Calon Guru Biologi. 1(1), 1-8.

Machali, I. (2014). Kebijakan Perubahan Kurikulum 2013 dalam Menyongsong Indonesia Emas Tahun 2045. Jurnal Pendidikan Islam, 3(1), 71. https://doi.org/10.14421/jpi.2014.31.71-94

Madden, D. (2019). Ranked: The Ten Countries With The Most Endangered Species In The World. https://www.forbes.com/sites/duncanmadden/2019/05/26/ranked-the-ten-countries-with-the-mostendangered-species-in-the-world/?sh=25124920461a 
Novak, J. ., \& Gowin, B. D. (1984). Learning How to Learn. In Angewandte Chemie International Edition, 6(11), 951-952. (New York). Cambridge University Press.

Nurpratiwi, S. F., Anggraeni, S., \& Supriatno, B. (2020). Analisis dan Rekontruksi Komponen Lembar Kerja Peserta Didik Pada Praktikum Tulang. Jurnal Biodik, 6(2), 372-383.

Olomola, D. B., Aguda, S. Y., Olorode, E. M., Oyediran, R. I., \& Adekunle, E. . (2019). The Aplication of Biotechnology in Biodiversity Conservation. 5(12), 55-63.

Putri, R. R., Ahda, Y., \& Darussyamsu, R. (2018). Analisis Aspek Kemampuan Berpikir Tingkat Tinggi pada Instrumen Penilaian Materi Protista untuk Peserta Didik SMA / MA Kelas X. Jurnal Biodik, $4(1), 8-17$.

Ramli, M. (2015). Implementasi Riset Dalam Pengembangan Higher Order Thinking Skills Pada Pendidikan Sains. Seminar Nasional Pendidikan Sains V, November, 6-17.

Redford, K. H., \& Richter, B. D. (1999). Conservation of biodiversity in a world of use. Conservation Biology, 13(6), 1246-1256. https://doi.org/10.1046/j.1523-1739.1999.97463.x

Schneiderhan-Opel, J., \& Bogner, F. X. (2020). How fascination for biology is associated with students' learning in a biodiversity citizen science project. Studies in Educational Evaluation, 66(October 2019). https://doi.org/10.1016/j.stueduc.2020.100892

Sofyan, F. A. (2019). Implementasi Hots Pada Kurikulum 2013. Inventa, 3(1), 1-9. https://doi.org/10.36456/inventa.3.1.a1803

Supriatno, B. (2018). Praktikum untuk Membangun Kompetensi. Proceeding Biology Education Conference, 15(1), 1-18.

Tinch, R., Balian, E., Carss, D., de Blas, D. E., Geamana, N. A., Heink, U., Keune, H., Nesshöver, C., Niemelä, J., Sarkki, S., Thibon, M., Timaeus, J., Vadineanu, A., van den Hove, S., Watt, A., Waylen, K. A., Wittmer, H., \& Young, J. C. (2018). Science-policy interfaces for biodiversity: dynamic learning environments for successful impact. Biodiversity and Conservation, 27(7), 1679 1702. https://doi.org/10.1007/s10531-016-1155-1

Wolff, L. A., \& Skarstein, T. H. (2020). Species learning and biodiversity in early childhood teacher education. Sustainability (Switzerland), 12(9), 9-11. https://doi.org/10.3390/su12093698

Yulianto, T., Pramudya, I., \& Slamet, I. (2019). Effects of the 21st Century Learning Model and ProblemBased Models on Higher Order Thinking Skill. International Journal of Educational Research Review, 4, 749-755. https://doi.org/10.24331/ijere.629084 